Marquette University

e-Publications@Marquette

School of Dentistry Faculty Research and

Publications

Dentistry, School of

7-2017

\title{
Ultraviolet-induced Surface Grafting of Octafluoropentyl Methacrylate on Polyether Ether Ketone for Inducing Antibiofilm Properties
}

\author{
Parisa Amdjadi \\ Shahid Beheshti University \\ Hanieh Nojehdehian \\ Shahid Beheshti University \\ Farhood Najafi \\ Institute for Color Science and Technology \\ Amir Ghasemi \\ Shahid Beheshti University \\ Massoud Seifi \\ Shahid Beheshti University
}

See next page for additional authors

Follow this and additional works at: https://epublications.marquette.edu/dentistry_fac

Part of the Dentistry Commons

\section{Recommended Citation}

Amdjadi, Parisa; Nojehdehian, Hanieh; Najafi, Farhood; Ghasemi, Amir; Seifi, Massoud; Dashtimoghadam, Erfan; Fahimipour, Farahnaz; and Tayebi, Lobat, "Ultraviolet-induced Surface Grafting of Octafluoropentyl Methacrylate on Polyether Ether Ketone for Inducing Antibiofilm Properties" (2017). School of Dentistry Faculty Research and Publications. 302.

https://epublications.marquette.edu/dentistry_fac/302 


\section{Authors}

Parisa Amdjadi, Hanieh Nojehdehian, Farhood Najafi, Amir Ghasemi, Massoud Seifi, Erfan Dashtimoghadam, Farahnaz Fahimipour, and Lobat Tayebi 
Marquette University

\section{e-Publications@Marquette}

\section{Dentistry Faculty Research and Publications/School of Dentistry}

This paper is NOT THE PUBLISHED VERSION; but the author's final, peer-reviewed manuscript. The published version may be accessed by following the link in th citation below.

Journal of Biomaterials Applications, Vol. 32, No. 1 (July1, 2017): 3-11. DOI. This article is (C) SAGE Publications and permission has been granted for this version to appear in e-Publications@Marquette. SAGE Publications does not grant permission for this article to be further copied/distributed or hosted elsewhere without the express permission from SAGE Publications.

\section{Ultraviolet-Induced Surface Grafting of Octafluoropentyl Methacrylate on Polyether Ether Ketone for Inducing Antibiofilm Properties}

\section{Parisa Amdjadi}

School of Dentistry, Shahid Beheshti University of Medical Sciences, Tehran, Iran Marquette University School of Dentistry, Milwaukee, WI

\section{Hanieh Nojehdehian}

School of Dentistry, Shahid Beheshti University of Medical Sciences, Tehran, Iran

Dental Research Center, Research Institute of Dental Sciences, School of Dentistry, Shahid Beheshti University of Medical Sciences, Tehran, Iran

School of Advanced Technologies in Medicine, Shahid Beheshti University Medical Sciences, Tehran, Iran

Farhood Najafi

Institute for Color Science and Technology, Tehran, Iran

Amir Ghasemi

School of Dentistry, Shahid Beheshti University of Medical Sciences, Tehran, Iran

Massoud Seifi 
School of Dentistry, Shahid Beheshti University of Medical Sciences, Tehran, Iran

Marquette University School of Dentistry, Milwaukee, WI, USA

\section{Erfan Dashtimoghadam}

Marquette University School of Dentistry, Milwaukee, WI, USA

\section{Farahnaz Fahimipour}

Marquette University School of Dentistry, Milwaukee, WI, USA

\section{Lobat Tayebi}

Marquette University School of Dentistry, Milwaukee, WI, USA

\section{Abstract}

Since octafluoropentyl methacrylate is an antifouling polymer, surface modification of polyether ether ketone with octafluoropentyl methacrylate is a practical approach to obtaining anti-biofilm biocompatible devices. In the current study, the surface treatment of polyether ether ketone by the use of ultraviolet irradiation, so as to graft (octafluoropentyl methacrylate) polymer chains, was initially implemented and then investigated. The Fourier-transform infrared and nuclear magnetic resonance spectra corroborated the appearance of new signals associated with the fluoroacrylate group. Thermogravimetric curves indicated enhanced asymmetry in the polymer structure due to the introduction of the said new groups. Measuring the peak area in differential scanning calorimetry experiments also showed additional bond formation. Static water contact angle measurements indicated a change in wettability to the more hydrophobic surface. The polyether ether ketoneoctafluoropentyl methacrylate surface greatly reduced the protein adsorption. This efficient method can modulate and tune the surface properties of polyether ether ketone according to specific applications.

Keywords Polyether ether ketone, surface treatment, polymer grafting, ultraviolet functionalizing, octafluoropentyl methacrylate, protein repellent

\section{Introduction}

Polyether ether ketone (PEEK) is a high-performance polymer consisting of repeating units of polyether and benzophenone units in the backbone. Outstanding mechanical properties, exceptional chemical stability, high hydrolysis resistance and biological inertness, have made PEEK a promising material for wide variety of biomedical applications, such as orthopedic devices.. . 2 PEEK polymer is also a suitable candidate for replacement of metal, ceramic, and polymeric dental materials due to aesthetic, light weight, and shock absorption properties. $-\underline{3}$ The aforementioned polymer is used in dental technology, i.e. abutments, fixed prosthetic frameworks, removable partial denture frameworks, orthodontic removable appliances, brackets, and wires. $\frac{4,5}{5}$

However, PEEK-based materials, like most of the dental devices that have contact with physiological fluids possess inadequacies, including nonspecific protein and bacterial adhesion. $-\underline{-}-\underline{T}$ The uncontrolled adhesion of biological compounds on the surface of dental materials is an undesirable phenomenon that causes the deterioration of function and a concern for the long-term application. $\underline{\underline{8}} \underline{-12}$

Salivary glycoproteins cover all surfaces in the oral cavity, seconds after cleaning. Microorganisms adhere to this layer and form biofilms organized as bacterial groups, virus, and fungi. $\frac{13}{3}$ Increased numbers of microorganisms with pathological ability will increase the risk of developing secondary caries along restorations, fungal infections related to complete dentures, and progression of periodontal disease on teeth supporting a partial denture or dental implants. Treatment of infected implants is difficult, as most of the bacteria are in a low metabolism phase of growth and less susceptible to antibiotic therapy. This infection is usually diagnosed at a late stage 
when the surrounding tissue has already been affected. The mature biofilm resist toward host immune response and antibiotic treatments. Thus, the best way to avoid the infection of implantable devices is to avoid the initial


render the PEEK surface anti-fouling capable.

Successful application of materials primarily relies on the properties of its surface. PEEK's inert surface has limited its applications; therefore, altering the surface reactivity of PEEK is a significant task that must be solved to fully realize the potential profits.

Two main strategies have been employed to improve the surface efficiency of polymers, exposure to highenergy species such as ultraviolet (UV) light, plasma, and $\mathbf{p}$-rays, $\underline{\underline{15}}, \underline{\underline{16}}$ and wet chemical methods. $\underline{\underline{17}} \underline{\underline{19}}$ However, several transitional steps in chemical methods usually result in undesirable byproducts due to the incidence of competition reactions. .20

Compared with other modification methods, UV surface graft polymerizations reveal some advantages including distribution of the grafted chains in a thin layer near the surface without damaging the bulk material. $\underline{21}$ As a result, this functionalized polymer can have both desirable surface and mechanical properties.

Fluoropolymers have been introduced as antifouling materials, and show many exceptional properties as high thermal and chemical resistance, and improved biocompatibility. Therefore, these polymers have been involved in many applications such as chemical resistant, antifouling, and noncorrosive coatings. $\underline{22}$

Several deposit resistance medical devices have been developed by utilizing octa fluoro pentyl(meth)acrylate (OFPA) polymers and have been used clinically; examples include contact lenses, intraocular lenses, vascular stents, corneal implants, and catheters. Therefore, the efficacy and safety of this polymer as an antifouling biomaterial is well-established. $. \underline{7} \underline{23}-\underline{25}$

Octafluoropentyl(meth)acrylate was studied in the present research because of its unique properties as excellent anti-biofouling material. Surface modification of PEEK with the OFPA polymer is effective for obtaining anti-biofilm biocompatible devices. The functionalized PEEK was characterized by Fourier-transform infrared (FTIR) spectroscopy, X-ray photoelectron spectroscopy (XPS), thermogravimetric analysis (TGA), differential scanning calorimetry (DSC), solid state nuclear magnetic resonance (NMR), laser scanning microscopy, and contact angle measurements. Biofilm adsorption was determined by the bicinchoninic acid (BCA) method.

In this study, we have demonstrated the fabrication of antifouling biocompatible PEEK biomaterials, by grafting OFPA-on PEEK surface using UV-induced reaction for developing multifunctional dental devices, which are in direct contact with salivary glycoproteins such as fixed and removable dental prosthesis or orthodontic appliances.

\section{Experimental section}

\section{Materials}

PEEK powder (10 microns) was obtained from VICTREX ${ }^{\circledR}$ (150UF10). Octafluoropentyl (meth) acrylate was used as obtained from Sigma-Aldrich, USA. PEEK powder was cleaned prior to use by refluxing in acetone for $48 \mathrm{~h}$ at $60^{\circ} \mathrm{C}$ with continuous stirring, and subsequently dried in an oven at $60^{\circ} \mathrm{C}$ for $24 \mathrm{~h}$ and stored under nitrogen.

\section{General procedure}

OFPA functionalized PEEK powder was obtained by UV-initiated photo-grafting (schematically illustrated in Figure 1). OFPA ( $2 \mathrm{~g}$ ) was added to methanol (12 cc) and degassed by purging $\mathrm{N}_{2}$ gas for $30 \mathrm{~min}$, then transferred to the degassed PEEK powder $(6 \mathrm{~g})$, with continuous stirring and exposed to UV lamp (1000 W, 
$360 \mathrm{~nm}$ ) at a distance of $10 \mathrm{~cm}$ for $45 \mathrm{~s}$. The powder was rinsed with the ethanol to remove non-grafted polymers and dried in vacuum oven at $40^{\circ} \mathrm{C}$ for $4 \mathrm{~h}$.

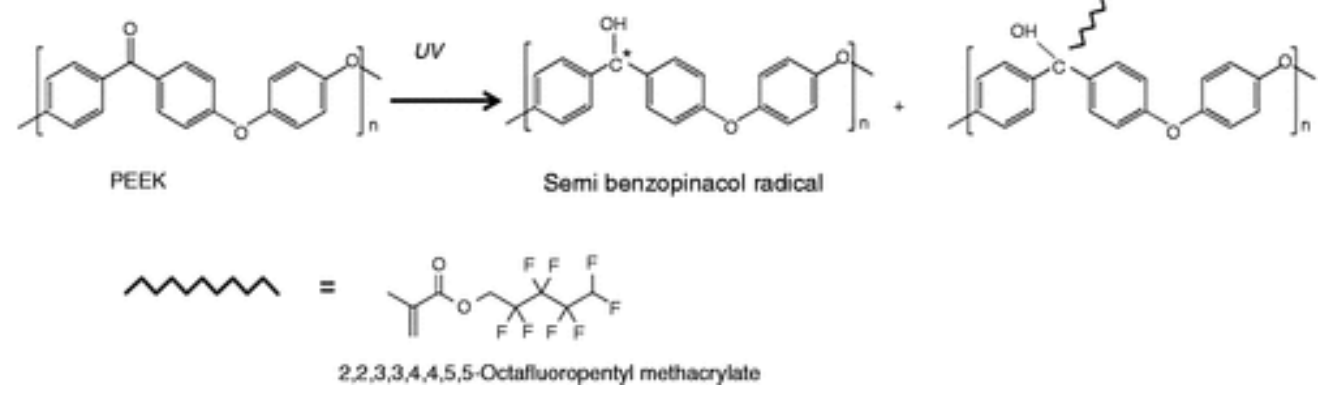

Figure 1. Schematic illustration of UV-initiated photo grafting.

Surface analysis of OFPA-grafted PEEK

FTIR spectroscopy

The functional group vibrations of the OFPA-grafted PEEK surfaces were examined by FTIR spectroscopy (Nicolet iS5 Thermo Scientific ${ }^{\mathrm{TM}}$ USA, OMNIC'M ) over the range of $500-4000 \mathrm{~cm}^{-1}$ at a resolution of $4 \mathrm{~cm}^{-1}$. Four scans were collected for each sample.

XPS

The surface elemental condition of the OFPA-grafted PEEK was analyzed by XPS. An Al anode X-ray source was employed with a concentric hemispherical analyzer (Specs model EA10 plus) to analyze the surface composition. The chamber pressure during the XPS experiment was $10^{-9} \mathrm{mbar}$. Five scans were taken for each sample.

\section{TGA}

The thermal stability of the polymers was analyzed by TGA. The measurements were carried out using a TGA-50 (Shimadzu) at a heating rate of $10^{\circ} \mathrm{C} \mathrm{min}^{-1}$. The analysis was performed on samples with an average mass of $10 \mathrm{mg}$, under dynamic conditions from room temperature to $700^{\circ} \mathrm{C}$, under nitrogen gas purge of $50 \mathrm{~mL} \mathrm{~min}^{-1}$. For each degradation step, two characteristic temperatures were selected: $T_{i}$, the initial degradation temperature and $T_{\max }$, the temperature of maximum rate of degradation.

DSC

The glass transition and melting properties of the samples were investigated by DSC using NETZSCH DSC 404 F1 Pegasus ${ }^{\circledR}$ operating under argon flow. $10 \mathrm{mg}$ of each sample was first heated up to $200^{\circ} \mathrm{C}$ at a temperature rate of $10^{\circ} \mathrm{C} \mathrm{min}-1$, followed by cooling to room temperature at a rate of $5^{\circ} \mathrm{C} \mathrm{min}-1$, and then heated up to $450^{\circ} \mathrm{C}$ at a heating rate of $10^{\circ} \mathrm{C} \mathrm{min}^{-1}$. The glass transition and melting temperatures were taken as the peak onset in the calorimetric curves, respectively, and the ostensible enthalpies were calculated as normalized integrals of the corresponding peaks. The level of crystallinity was determined from the relation between the enthalpy of the modified sample and the value for crystalline control PEEK.

Nuclear magnetic resonance (NMR)

Solid-state cross-polarization/magic-angle-spinning (MAS) NMR spectra were recorded on a Bruker 500 spectrometer/imager (Bruker Analytik GmbH, Karlsruhe, Germany) with standard double-resonance probe head and frequencies of $10.5 \mathrm{kHz}$. During the detection period of the $\mathrm{C} 13$, magnetization dipolar decoupling was used to eliminate the strong heteronuclear dipolar coupling. 


\section{Contact angle}

The static water contact angles on the OFPA-grafted PEEK pellet surfaces were measured by the sessile drop method using a digital microscope camera (dinolite model AM 4113ZTS, USA).

\section{Laser microscopy}

Surface grafted polymer morphology obtained by Olympus ${ }^{\circledR}$ LEXT OLS4000 3D Laser Measuring Microscope. Scattering or fluorescence intensity provides information about each volume element (igire 2).

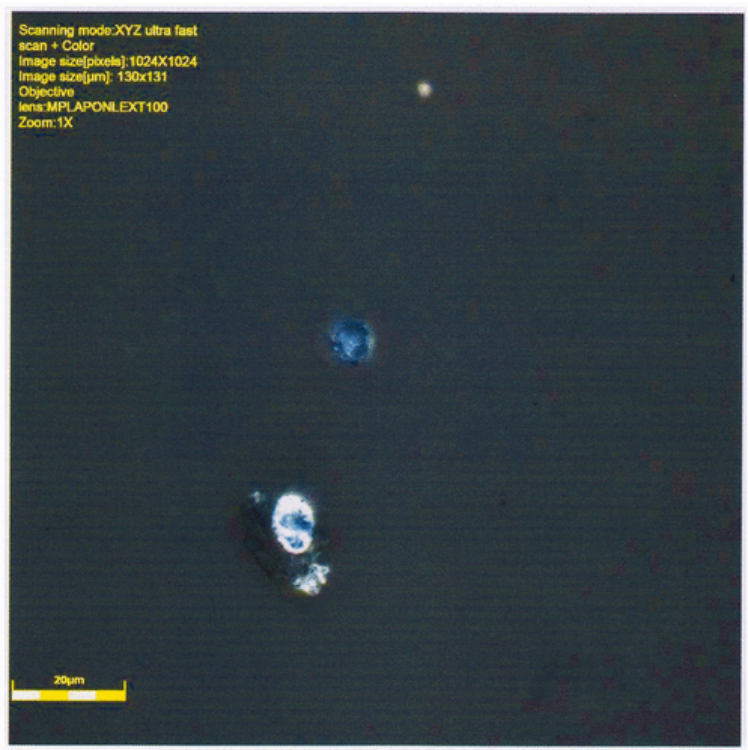

Figure 2. Laser microscopy, surface grafted polymer morphology.

\section{Characterization of protein adsorption}

Biofilm adsorption was determined by the BCA method. Samples were first immersed in phosphate-buffered saline (PBS) for $2 \mathrm{~h}$, and then in bovine serum albumin (BSA) at a concentration of $4.5 \mathrm{~g} / \mathrm{L}$ for $2 \mathrm{~h}$. The disks then were rinsed with fresh PBS for $5 \mathrm{~min}$, immersed in sodium dodecyl sulfate (SDS) $1 \mathrm{wt} \%$ in PBS, and sonication at room temperature for 20 min to entirely remove the BSA adsorbed onto the surface of the disk. A protein analysis kit (BCA protein assay kit, Thermo Scientific, USA) was used to determine the BSA concentration in the SDS solution. $\underline{26}, \underline{27}$

Data analysis

Comparison of protein adhesion data between control (PEEK) and experimental (PEEK-OFPA) groups was conducted by means of $t$-test statistical analysis (SPSS V17). The $p$-value of less than 0.05 was considered significant.

\section{Results and discussion}

Direct functionalization of PEEK is a difficult process, due to the insolubility in common organic solvents. We selected this approach for the direct functionalization, using benzophenone segment to generate free radicals on exposure to the UV radiations. The surface free radicals start free radical polymerization on interaction with available polymers, leading to polymer chains grafted PEEK surfaces. Grafting of OFPA chains on the PEEK surface exhibits the applicability of the proposed strategy. In order to estimate the effects of UV irradiation on the PEEK, we have tested the thermal stability using TGA and DSC. The thermal analysis clearly shows that PEEK polymer retains its stability, even after UV irradiation. The surface functionalization of PEEK membrane was confirmed by FTIR, XPS, and C NMR. Resistant toward the bio-adhesion was demonstrated by BCA method. 


\section{FTIR spectroscopy}

The surface functionalization of PEEK powder was studied by FTIR spectroscopy. Transmission peaks were observed at 1650, 1590, 1490, 1220, and $1150 \mathrm{~cm}^{-1}$ for both untreated PEEK and OFPA-grafted PEEK (Figure 3 ). These peaks are chiefly attributed to the diphenyl ether group, phenyl rings, and aromatic hydrogen in the PEEK polymer. $\underline{28} \underline{\underline{29}}$ However, absorption peaks at 1712 and $1050 \mathrm{~cm}^{-1}$ are observed only for OFPA-grafted PEEK. These peaks corresponded to the carbonyl group $(C=O)$ and fluoride group $(C-F)$ in the OFPA polymer. Broad peak band of $\mathrm{OH}$-group at $3400 \mathrm{~cm}^{-1}$ is related to $\mathrm{C}=\mathrm{C}$ radical bond of OFPA to PEEK polymer. The IR spectra of semicrystalline polymers containing the benzophenone segment present two carbonyl stretching vibrations: the main feature at $1590 \mathrm{~cm}^{-1}$ and a shoulder at $1650 \mathrm{~cm}^{-1}$, which represent the crystalline and amorphous phases, respectively. $\frac{30}{-}$ The spectra of the control PEEK and the derivatives with a lower degree of grafting display an overlapping of the two aforementioned absorptions; however, for functionalized PEEK, the stretching vibration seems to be mainly related to the amorphous phase. In order to quantitatively track the reduction process, the ratio between the area of the carbonyl peak at $1650 \mathrm{~cm}^{-1}$ and the unchanged reference area at $1490 \mathrm{~cm}^{-1}$, associated with the $\mathrm{C}-\mathrm{C}$ stretching of the aromatic rings, was calculated. The value decreased from 0.40 for the pure PEEK to 0.35 , which proves that the carbonyl group was effectively reduced. On the other hand, new absorption peaks can be visualized in the spectra of the PEEK derivative, which confirm the success of the reduction process.

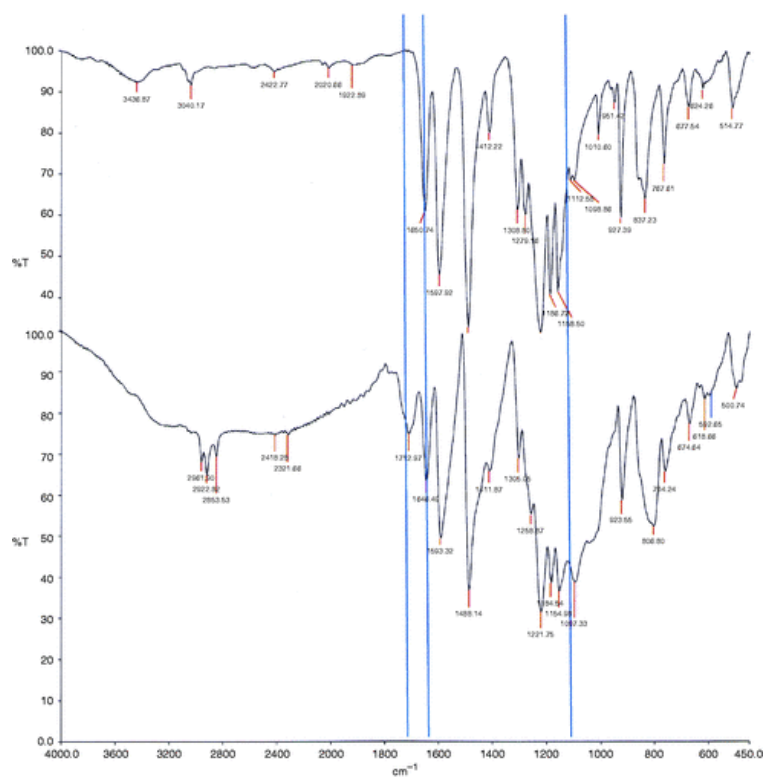

Figure 3. FTIR spectra of untreated (upper graph) and OFPA-grafted (lower graph) PEEK.

\section{TGA}

TGA is a useful method to evaluate the thermal stability of the material. The mass loss of polymeric material corresponds to the decomposition of the main chain. The thermogravimetric curves are shown in Figure 4 . Pure PEEK exhibits a single degradation stage that initiates $\left(T_{i}\right)$ at $530^{\circ} \mathrm{C}$ and shows the maximum rate of weight loss $\left(\mathrm{T}_{\max }\right.$ ) at $570^{\circ} \mathrm{C}$. At $700^{\circ} \mathrm{C}$, the residual mass is about $53 \%$ of the initial weight. OFPA-PEEK exhibits two distinct weight loss stages; the first maximum weight loss rate at $350^{\circ} \mathrm{C}$ may represent the premature degradation of the fluoroacrylate copolymer and showed the grafting degree of OFPA on the surface of PEEK particles. The second degradation stage of OFPA-PEEK begins at $480^{\circ} \mathrm{C}$, about $50^{\circ} \mathrm{C}$ lower than PEEK, whereas for the compound with higher degree of functionalization the decrease is considerably stronger, higher than $100^{\circ} \mathrm{C}$, which could be explained by significant asymmetry in the polymer structure due to the new side groups that render it less stable. $\stackrel{31}{ }$ 


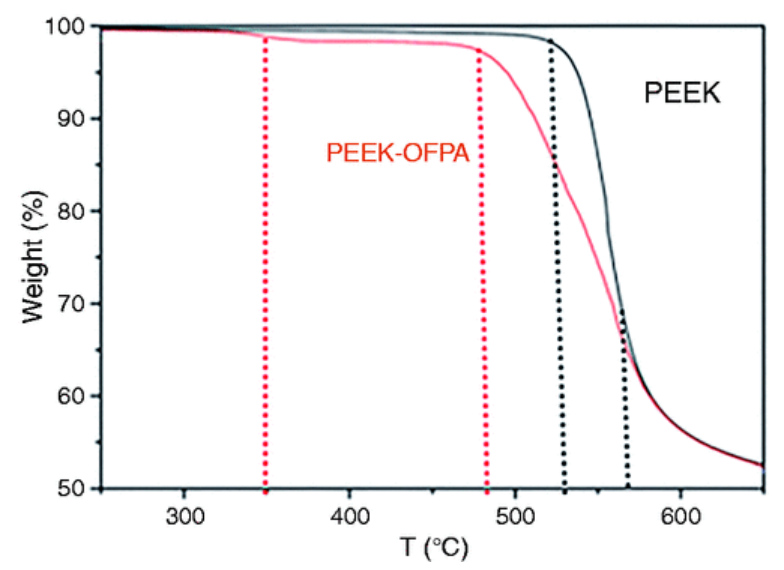

Figure 4. TG curves for PEEK and PEEK-OFPA.

XPS

The XPS measurements were carried out to determine the surface chemical compositions of PEEK-OFPA (Figure 5). The XPS of pristine PEEK showed signals at 533 and $286 \mathrm{eV}$ corresponding to O1s and C1s orbitals,

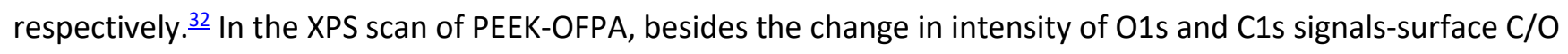
atomic ratio, a new signal for $\mathrm{F} 1 \mathrm{~s}$ at $685 \mathrm{eV}$ is observed. The high-resolution XPS revealed peaks for $\mathrm{C}-\mathrm{C}, \mathrm{C}-\mathrm{O}$, and $\mathrm{C}=\mathrm{O}$ at $284.5,286.6$, and $288.5 \mathrm{eV}$, and also new peaks at $\sim 291.5$ related to $\mathrm{CF} 2$, which verified the surface modification with fluoroacrylate moieties.

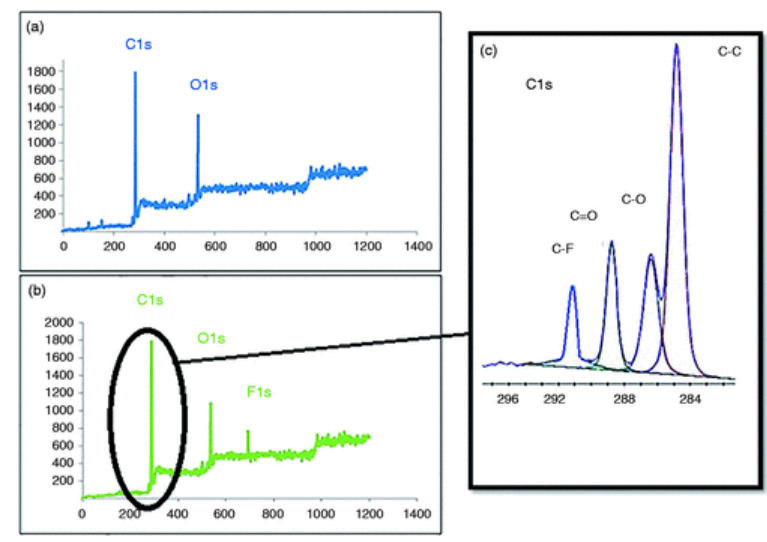

Figure 5. The elemental compositions on the surface detected by XPS. (a) XPS spectra of pristine peek; (b) OFPAgrafted PEEK; (c) high-resolution C1s spectra of PEEK-OFPA.

\section{NMR}

C-13 spectra were run on both samples to monitor the reduction of the ketone group from the benzophenone segment and covalent attachment of OFPA (Figure 6). Chemical shift signals can be observed in the spectra, caused by the anisotropic nuclear magnetic interactions of the carbon nuclei and the homonuclear dipole

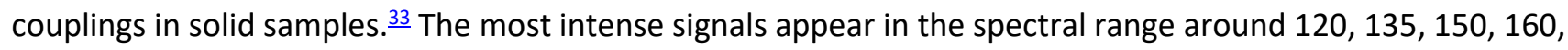
and $193 \mathrm{ppm}$ for both samples, associated with the carbons of the aromatic rings. A close analysis reveals the gradual diminution of the intensity of the peak at around $193 \mathrm{ppm}$, associated with the carbon of the carbonyl group and, the appearance of a new signal at $62 \mathrm{ppm}$, related to the carbon linked to the hydroxyl group. These results also indicate that the functionalization of PEEK has been perfectly carried out without disturbing the ketonic group, which is present in the main backbone of PEEK. Therefore, the NMR study further supports the results obtained from FTIR. 


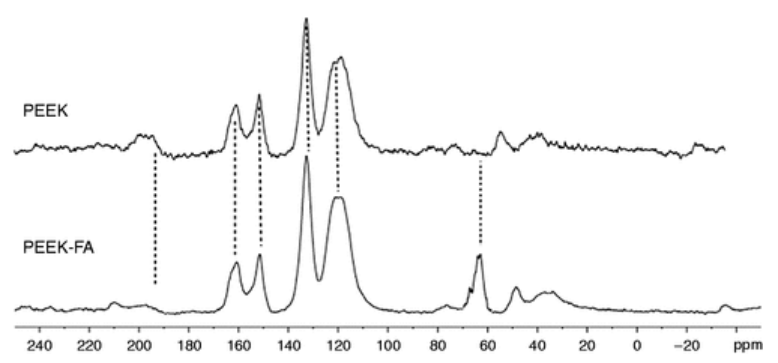

Figure 6. C-NMR of PEEK and PEEK-OFPA.

\section{DSC}

DSC technique provides quantitative and qualitative information about physical and chemical changes that involve endothermic or exothermic reaction in the material, which relates to molecular vibration before and after processing. As PEEK melts and decomposes at higher temperatures than OFPA, it is important to study how the presence of OFPA on a particle's surface would influence the thermal behavior of the polymer.

DSC experiments run on samples of PEEK and OFPA grafted PEEK powder. A comparison between the DSC heating curves is shown in Figure 7. As for the grafted PEEK, the first endothermic peaks shift to a higher temperature range $\left(219\right.$ to $\left.225^{\circ} \mathrm{C}\right)$. This could be attributed to strong interactions between OFPA and the surface of PEEK polymer. Tg shift to a higher temperature, indicating that the molecules lose mobility. The substituent groups enable the formation of strong inter and intramolecular bonds between the polymeric segments that limit the polymer chain diffusion. The covalent bonds between the OFPA and the surface of PEEK polymer cause higher energy requirements to attain the glassy state before reaching the $\mathrm{Tg}$ due to less chain mobility. ${ }^{34}$ The exothermic peak energy area can be used to assess additional bond formation. The melting point of PEEK derivative is similar to that of native PEEK, indicating the crystalline structure of the polymer did not change significantly during modification. $\frac{35}{}$

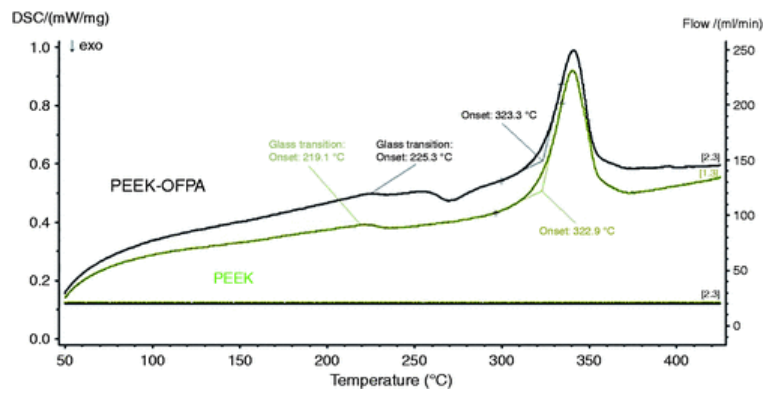

Figure 7. DSC analysis of pristine PEEK and OFPA grafted PEEK.

\section{The static-water contact angles}

Drops of purified water $(0.05 \mathrm{cc})$ were deposited on the OFPA-grafted PEEK disk surfaces, and the contact angles were directly measured after $10 \mathrm{~s}$ of dropping. Measurements were repeated 10 times for each sample, and the average values were regarded as the contact angles. $C A=77.3$ for PEEK that turned into higher hydrophobicity with CA of 88.1. This change in surface wettability correlates with the change in the surface electrostatic charge.

\section{Characterization of protein adsorption}

The adsorption of proteins can be diminished by either thermodynamic or kinetic control decreasing the interaction between protein and the surface by eliminating the attractive forces between them is thermodynamic control. Kinetic control can be achieved by incorporation of barriers to slowing down the rate of protein adsorption, for example, by the introduction of long-range repulsive forces through polymer grafting. $\frac{36}{6}$ 
Hydrophobic coatings are used to prevent nonspecific adsorption of biological materials. Grafting of hydrophobic, protein-repellent fluoropolymer brushes onto the specific structures opens a new door to fabricating long-term antifouling coatings on various substrates. ${ }^{37}$ To date, there has been no report on proteinrepellent PEEK polymers.

Protein adsorption onto disk surfaces is plotted in Figure 8 (mean $\pm S D ; n=6$ ). Preliminary examination of the data suggested differences in the protein-surface adhesion; the PEEK-OFPA surface greatly reduced the protein adsorption compared to the control group $(p<0.05)$. The PEEK-OFPA samples were found to retain their protein-resistance properties, even after 3 months of aging in distilled water.

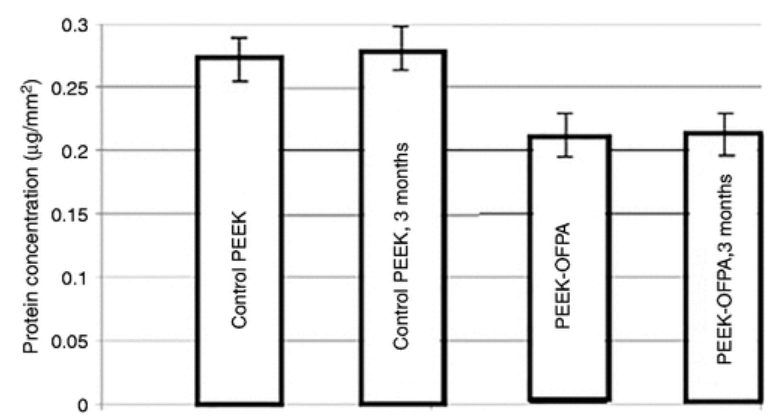

Figure 8. The quantitative evaluation of protein adsorption on PEEK, PEEK-OFPA, PEEK 3 month, and PEEK-OFPA 3 month.

\section{Conclusion}

A wide range of materials is used for different clinical and biomedical applications. However, in order to comply with the conditions of biocompatibility, their surface generally needs to be altered. The properties of the surface determine the appropriate application of the material and the final strategy for its modification. In the present research, it was demonstrated that UV activation provides an efficient method for the decoration of PEEK surfaces with OFPA under mild condition. UV-irradiation produces a high-concentration of semi-benzopinacol radical on the surface, which can initiate the graft-from polymerization of the available monomer as the main reaction. High concentration of OFPA (as protein repellent monomer) in the reaction system leads to the selfinitiated surface graft polymerization between the radicals on the PEEK surface and the OFPA monomer, forming the high-density graft chain on the area. The OFPA graft layer density is greatly controlled by the concentration of free radicals and monomers. This approach is a simple single step and low-cost route to functional PEEK with significant characteristics for use as protein repellent dental appliances, which are in contact with salivary glycoproteins. This strategy is also accessible for a wide range of other polymers as grafting medium.

\section{Declaration of Conflicting Interests}

The author(s) declared no potential conflicts of interest with respect to the research, authorship, and/or publication of this article.

\section{Funding}

The author(s) disclosed receipt of the following financial support for the research, authorship, and/or publication of this article: Financial support was provided by the Dental Research Center Research Institute of Dental Sciences, School of Dentistry, Shahid Beheshti University of Medical Sciences, Tehran, Iran. 


\section{References}

1. $\quad$ Pruitt, L, Furmanski, J. Polymeric biomaterials for load-bearing medical devices. JOM 2009; 61: 14-20.

2. SMK, Devine, JN . PEEK biomaterials in trauma,orthopedic, and spinal implants. Biomaterials 2008; 28: 4845-4869.

3. Najeeb, S, Zafar, MS, Khurshid, Z. Applications of polyetheretherketone (PEEK) in oral implantology and prosthodontics. J Prosthodont Res 2016; 60: 12-19.

4. Zoidis, P, Papathanasiou, I, Polyzois, G. The use of a modified poly-ether-ether-ketone (PEEK) as an alternative framework material for removable dental prostheses. A clinical report. J Prosthodont 2016; 25: 580-584.

5. Maekawa, M, Kanno, Z, Wada, T. Mechanical properties of orthodontic wires made of super engineering plastic. Dental Mater J 2015; 34: 114-119.

6. Wang, LZH . Study of oral microbial adhesion and biofilm formation on the surface of nanofluorohydroxyapatite/polyetheretherketone composite. Zhonghua Kou Qiang Yi Xue Za Zhi 2015; 50: 378-382.

7. Linhardt JG, Kunzler JF and Shipp DA. inventorsBiomedical devices. Patent 20090169716 A1, USA, 2009.

8. Mouhyi, J, Dohan, Ehrenfest, DM, Albrektsson, T. The peri-implantitis: implant surfaces, microstructure, and physicochemical aspects. Clin Implant Dent Relat Res 2012; 14: 170-183.

9. Campoccia, D, Montanaro, L, Arciola, CR. The significance of infection related to orthopedic devices and issues of antibiotic resistance. Biomaterials 2006; 27: 2331-2339.

10. Sanpo, N, Tan, ML, Cheang, P. Antibacterial property of cold-sprayed HAAg/PEEK coating. J Therm Spray Technol 2009; 18: 10-15.

11. del, Pozo, JL, Patel, R. The challenge of treating biofilm-associated bacterial infections. Clin Pharmacol Therap 2007; 82: 204-209.

12. Trampuz, A, Zimmerli, W. Diagnosis and treatment of implant-associated septic arthritis and osteomyelitis. Curr Infect Dis Rep 2008; 10: 394-403.

13. Filoche, S, Wong, L, Sissons, CH. Oral biofilms: emerging concepts in microbial ecology. J Dent Res 2010; 89: 8-18.

14. Mathew, KSR . Emerging nanotechnologies in dentistry, New York: Elsevier, 2012.

15. Kim, S, Lee, KJ, Seo, Y. Polyetheretherketone (PEEK) surface functionalization by low-energy ion-beam irradiation under a reactive $\mathrm{O}_{2}$ environment and its effect on the PEEK/copper adhesives. Langmuir 2004; 20: 157-163.

16. Kato, K, Uchida, E, Kang, E-T. Polymer surface with graft chains. Progr Polym Sci 2003; 28: 209-259.

17. Zhao, B, Brittain, WJ. Polymer brushes: surface-immobilized macromolecules. Progr Polym Sci 2000; 25: 677-710.

18. Bhattacharya, A, Misra, BN. Grafting: a versatile means to modify polymers: Techniques, factors and applications. Progr Polym Sci 2004; 29: 767-814.

19. Goddard, JM, Hotchkiss, JH. Polymer surface modification for the attachment of bioactive compounds. Progr Polym Sci 2007; 32: 698-725.

20. Gao, $X$, Wang, $R$, Zhang, A. Synthesis of poly(ether ether ketone)s containing tertiary amine. Mater Lett 2007; 61: 3647-3651.

21. Deng, J, Wang, L, Liu, L. Developments and new applications of UV-induced surface graft polymerizations. Progr Polym Sci 2009; 34: 156-193.

22. Yao, W, Li, Y, Huang, X. Fluorinated poly(meth)acrylate: Synthesis and properties. Polymer 2014; 55: 6197-6211.

23. Linhardt JG, Shipp DA, Kunzler JF, et al. Coating solutions comprising segmented interactive block copolymers. Google Patents, 2009.

24. Lang W and Lai YC. Surface modified biomedical devices. Google Patents, 2011.

25. Tamura T, Takeuchi K, Taniguchi M, et al. Biocompatible polymeric compound, biocompatible polymer and polymer particles. Google Patents, 2010. 
26. Kratz, FMC . Characterization of protein films ondental materials: Bicinchoninic acid assay (BCA) studieson loosely and firmly adsorbed protein layers. Phys Status Solidi (a) 2013; 210: 964-967.

27. Sibarani, J, Takai, M, Ishihara, K. Surface modification on microfluidic devices with 2methacryloyloxyethyl phosphorylcholine polymers for reducing unfavorable protein adsorption. Colloids Surf B: Biointerfaces 2007; 54: 88-93.

28. Kyomoto, M, Ishihara, K. Self-initiated surface graft polymerization of 2-methacryloyloxyethyl phosphorylcholine on poly(ether ether ketone) by photoirradiation. ACS Appl Mater Interfaces 2009; 1: 537-542.

29. He, D, Susanto, H, Ulbricht, M. Photo-irradiation for preparation, modification and stimulation of polymeric membranes. Progr Polym Sci 2009; 34: 62-98.

30. GE, MN, CM, Hendra, PJ. Fourier transform Raman spectroscopy in the study of technological polymers; Part 1: poly(aryl ether ketones), their composites and blends. Spectrochim Acta Part A: Mol Biomol Spectrosc 1997; 53: 2279-2294.

31. Hu, S, Chen, S, Menzel, R. Aqueous dispersions of oligomer-grafted carbon nanomaterials with controlled surface charge and minimal framework damage. Faraday Discussions 2014; 173: 273-285.

32. Yameen, B, Álvarez, M, Azzaroni, O. Tailoring of poly(ether ether ketone) surface properties via surfaceinitiated atom transfer radical polymerization. Langmuir 2009; 25: 6214-6220.

33. Díez-Pascual, A, Martínez, G. Synthesis and characterization of poly(ether ether ketone) derivatives obtained by carbonyl reduction. Macromolecule 2009; 42: 6885-6892.

34. Zeleznak, KJ, Hoseney, RC. The glass transition in starch. Cereal Chem 1987; 64: 121-124.

35. Chung, TC . 6 - Functionalization via Reactive Polyolefins Containing Borane Groups. Functionalization of Polyolefins, London: Academic Press, 2002, pp. 81-104.

36. Fang, Szleifer, I. Effect of molecular structure on the adsorption of protein on surfaces with grafted polymers. Langmuir 2002; 18: 5497-5510.

37. Wang, Z, Zuilhof, H. Self-healing superhydrophobic fluoropolymer brushes as highly protein-repellent coatings. Langmuir 2016; 32: 6310-6318. 